\title{
A Novel Curriculum Visualization Method Using a Combination of Competencies, Cosine Similarity, Multidimensional Scaling Methods, and Scatter Plotting
}

\author{
Kunihiko Takamatsu *, Katsuhiko Murakami `, Yasuhiro Kozaki *, \\ Kenya Bannaka *, Ikuhiro Noda *, Mayumi Yamasaki *, \\ Kenichiro Mitsunari *, Tadashi Nakamura *, \\ Yasuo Nakata *
}

\begin{abstract}
This article outlines a new way of visualizing curricula (sets of courses for students) using competencies via a combination of cosine similarity, multidimensional scaling methods, and scatter plotting. We have already published a report analyzing syllabi (summary texts that explain the main points of courses or the contents of curricula) with the same methods. In this report, we show that using competencies is more useful than using syllabi. Usually, students are only interested in the course content when they select courses; this new visualization of curricula using competencies gives students a new perspective on their courses.
\end{abstract}

Keywords: competency, cosine similarity, multidimensional scaling methods, scatter plotting, visualizing curricula

\section{Introduction}

Over the past decade, the circumstances in which Japanese universities find themselves have changed significantly. During the 2016 International Conference on Data Science and Institutional Research (DSIR 2016), we reported on enhanced collaboration between faculty and staff at Kobe Tokiwa University, using a strength, weaknesses, opportunities, and threats (SWOT) framework, as well as complex network analysis methods [1]. Our results led to the creation of a team at the university. In this article, we report on the team's activities and data, which we analyze using information gathered by the team.

\subsection{Preparation for Reform in Higher Education}

\footnotetext{
* Kobe Tokiwa University, Hyogo, Japan

The University of Tokyo, Tokyo, Japan

* Osaka Kyoiku University, Osaka, Japan
} 
In December 2015, a team for university reform was built; it would serve under the president's team [2]. The team had the following three main goals.

(1) To lay the foundations for managing learning and teaching and for university reform

(2) To foster advanced collaboration between faculty and staff

(3) To lay the foundations for liberal arts at the university

With regard to the first goal, managing learning and teaching consists of the "design, operation, and management of an educational system in order to achieve university-wide educational goals" [3]. To this end, the Japanese Central Council for Education (CCE), a part of the Ministry of Education, Culture, Sports, Science, and Technology (MEXT) [4], published a report on the future of higher education in Japan in 2008 that proposed integrating admissions policy (AP), curriculum policy (CP), and diploma policy (DP) in Japanese universities.

In response to the report, all faculty members at our university were asked to be involved in defining each of these three policies; previously, the faculty members at our university had had no influence on these policies, as is generally the case in Japan [5].

Our team proposed forming a relationship between faculty members and the president's team around these three polices. Because our university had no unified policies, we also proposed integrating AP, CP, and DP. We suggested that in order to enhance teaching management, an assessment policy (AsP) should be added, following CCE recommendations [6].

We also proposed a new policy called the student support policy (SSP). AP, CP, and DP deal only with regular curricula, and we thought that it was important for students to be exposed not only to regular curricula but also to quasi-regular and extracurricular activities. Quasi-regular curricula are used in remedial education, and extracurricular activities consist of volunteer and club activities.

To consistently evaluate and connect the aforementioned policies (AP, CP, DP, AsP, and SSP), we needed to create a common evaluation indicator. Therefore, we developed "Tokiwa Competency," a competency that students acquire through regular, quasi-regular, and extracurricular activities (Table 1, cited from [7]). In this article, we use Spady's definition of competency, which is a visualized, functionally linked network of knowledge, skills, and attitudes that enables successful task performance and problem-solving [8]. Ehime University, in 2012, defined Ehime University Competencies Standards for Students (EUCS-S) [9]. This is different from DP in that it is the direction goal (the direction to be aimed) of the students of Ehime University. The faculty and staff in Ehime University continue to actively participate with students to obtain the specific ability to be listed in the EUCS-S [9]. In addition, as a result of retrieval using "university, competency" as a key word, Kansai Gaidai University[10] and Kanto Gakuen University [11] each had a unique competency of the university. The "Tokiwa Competency" was created with reference to these competencies.

The second aim of the team — to foster advanced collaboration between faculty and staff- 
was achieved through the Research Cooperative Division (RCD), made up of both faculty and staff, mostly those on the team, to facilitate congenial relationships between faculty and staff and the team.

In contrast to the present situation at our university, until several years ago, there was a clear distinction between faculty and staff at universities [12]. In recent times, the importance of joint work by faculty and staff has been recognized [13]. The team has already published reports on cooperative efforts between faculty and staff and has proposed novel perspectives that were produced using knowledge co-created by them [14]. This article is based on the knowledge model that we proposed in [15] and [16].

The third purpose of the team - to build a foundation for liberal arts at the university - was achieved in part through the establishment of the Educational Innovation Organization (EINO) and their work with the team; some authors of this article are members of the EINO. EINO members had previously tried to create common liberal and general education curricula, but this was impossible because the EINO could not collect the opinions of every member.

However, the team helped the EINO to introduce liberal arts to the university by proposing draft versions of liberal arts courses to the president's team. Ultimately, the EINO prepared 40 courses using the recommendations of the team (Table 2).

In order to connect the proposed liberal arts courses with the five policies (AP, CP, DP, AsP, and SSP) and 19 competencies, the team, along with an AsP team from the EINO, discussed how to evaluate AP, CP, DP, AsP, and SSP using the competencies. We proposed using a rubric including the 19 competencies to assess the courses.

Rubrics are frequently used in elementary, junior high, and high schools, but hardly in higher education [17]. The president's team accepted this proposal and now uses the comprehensive syllabi for common liberal and general education courses, including the 19-competency rubric, for course evaluation.

We show the relationships between 40 courses and the 19 competencies at Kobe Tokiwa University in Table 2. Each syllabus of a course contains or shows both relational Tokiwa competencies and the rubric corresponding to the shown relational Tokiwa competencies [18]. Moreover, each course syllabus contains or shows evaluation methods and the evaluation ratio using Tokiwa competencies [18].

The ratios shown in Table 2 are collected from the syllabus of the 40 shortlisted courses. The ratio was defined by each teacher corresponding to each course, and therefore may serve as the ideal ratio that students will obtain when they study each course. 
Table 1: Kobe Tokiwa University competencies (cited from [7])

\begin{tabular}{|c|c|}
\hline $\begin{array}{l}\text { Abbreviated name of compe- } \\
\text { tency }\end{array}$ & Competency \\
\hline 1. Culture & $\begin{array}{l}\text { Ability to use liberal arts as the foundation of human nature, } \\
\text { which can involve a variety of people. }\end{array}$ \\
\hline 2. Common Sense & $\begin{array}{l}\text { Ability to behave sensibly and show sound judgment in prac- } \\
\text { tical matters. }\end{array}$ \\
\hline 3. Professional Expertise & $\begin{array}{l}\text { Having the necessary knowledge and skills to perform the } \\
\text { duties of each profession }\end{array}$ \\
\hline 4. Media Literacy & $\begin{array}{l}\text { Ability to collect, organize, and analyze necessary infor- } \\
\text { mation from various media sources for proper thinking and } \\
\text { judgment. }\end{array}$ \\
\hline 5. Logical Thinking & Ability to consider situations logically based on evidence. \\
\hline 6. Critical Thinking & $\begin{array}{l}\text { Ability to have a multilateral, critical perspective that can } \\
\text { grasp and consider various ideas. }\end{array}$ \\
\hline 7. Intellectual Curiosity & $\begin{array}{l}\text { Ability to be curious, to learn and remember things, and to } \\
\text { have fun and take pleasure in learning. }\end{array}$ \\
\hline 8. Exploration & Ability to think deeply about things and methods. \\
\hline 9. Continuity & $\begin{array}{l}\text { Ability to maintain a consistent stance on issues and act } \\
\text { knowledgeably and thoughtfully. }\end{array}$ \\
\hline 10. Self-Management & $\begin{array}{l}\text { Ability to manage one's physical and mental health appropri- } \\
\text { ately. }\end{array}$ \\
\hline 11. Reflection & $\begin{array}{l}\text { Ability to continually seek ways to improve oneself by re- } \\
\text { flecting on one's thinking and behavior. }\end{array}$ \\
\hline 12. Design Thinking & $\begin{array}{l}\text { Ability to design solutions and develop comprehensive } \\
\text { knowledge. }\end{array}$ \\
\hline 13. Presentation & $\begin{array}{l}\text { Ability to appropriately communicate one's personal feelings } \\
\text { and thoughts to others. }\end{array}$ \\
\hline 14. Judgment & $\begin{array}{l}\text { Ability to make appropriate decisions given the circum- } \\
\text { stances, based on valid information and sound thinking. }\end{array}$ \\
\hline 15. Implementation & $\begin{array}{l}\text { Ability to take specific actions based on one's feelings and } \\
\text { thoughts and without fear of failure. }\end{array}$ \\
\hline 16. Responsibility & $\begin{array}{l}\text { Ability to behave and face things responsibly as a member of } \\
\text { society. }\end{array}$ \\
\hline 17. Contribution & $\begin{array}{l}\text { Ability to feel happy for others and take actions that are use- } \\
\text { ful for others. }\end{array}$ \\
\hline 18. Communication & $\begin{array}{l}\text { Ability to listen to others' opinions, without which it is im- } \\
\text { possible to have a creative dialogue. }\end{array}$ \\
\hline 19. Cooperation \& Collaboration & $\begin{array}{l}\text { Ability to set aside personal and individual interests to work } \\
\text { together harmoniously. }\end{array}$ \\
\hline
\end{tabular}




\subsection{Curriculum Mapping}

Table 2: The relationships between 40 courses and the 19 competencies at Kobe Tokiwa University

\begin{tabular}{|c|c|c|c|c|c|c|c|c|c|c|c|c|c|c|c|c|c|c|c|c|}
\hline course name / competency & 1 & 2 & 3 & 4 & 5 & 6 & 7 & 8 & 9 & 10 & 11 & 12 & 13 & 14 & 15 & 16 & 17 & 18 & 19 & total \\
\hline 01.Pleasant \& Deep Learning I & 0 & 0 & 0 & 0 & 0 & 0 & 0 & 20 & 0 & 10 & 25 & 10 & 15 & 0 & 0 & 0 & 0 & 0 & 20 & 100 \\
\hline 02.Pleasant \& Deep Learning ॥ & 0 & 0 & 0 & 0 & 0 & 0 & 0 & 20 & 0 & 10 & 25 & 10 & 15 & 0 & 0 & 0 & 0 & 0 & 20 & 100 \\
\hline 03.Freshman Seminar I & 0 & 0 & 0 & 0 & 0 & 0 & 25 & 35 & 0 & 0 & 20 & 0 & 0 & 0 & 0 & 0 & 0 & 20 & 0 & 100 \\
\hline 04.Freshman Seminar II & 0 & 0 & 0 & 0 & 0 & 0 & 25 & 35 & 0 & 0 & 20 & 0 & 0 & 0 & 0 & 0 & 0 & 20 & 0 & 100 \\
\hline 05.Leadership \& Facilitation & 0 & 0 & 0 & 0 & 0 & 0 & 0 & 0 & 0 & 0 & 40 & 15 & 0 & 0 & 0 & 10 & 10 & 5 & 20 & 100 \\
\hline 06.Information Technology Basic & 35 & 0 & 0 & 35 & 30 & 0 & 0 & 0 & 0 & 0 & 0 & 0 & 0 & 0 & 0 & 0 & 0 & 0 & 0 & 100 \\
\hline 07.Health \& Sports Science II & 0 & 0 & 0 & 0 & 0 & 0 & 0 & 0 & 0 & 30 & 0 & 0 & 30 & 0 & 0 & 20 & 0 & 0 & 20 & 100 \\
\hline 08.Academic writing & 0 & 0 & 0 & 15 & 25 & 15 & 25 & 0 & 0 & 0 & 0 & 0 & 15 & 5 & 0 & 0 & 0 & 0 & 0 & 100 \\
\hline 09.English Communication I & 0 & 0 & 0 & 19 & 30 & 23 & 15 & 0 & 0 & 0 & 0 & 0 & 13 & 0 & 0 & 0 & 0 & 0 & 0 & 100 \\
\hline 10.English Communication II & 0 & 0 & 0 & 10 & 35 & 35 & 10 & 0 & 0 & 0 & 0 & 0 & 10 & 0 & 0 & 0 & 0 & 0 & 0 & 100 \\
\hline 11.Communicative English Basic & 0 & 0 & 0 & 0 & 0 & 0 & 20 & 0 & 0 & 0 & 0 & 0 & 60 & 0 & 0 & 0 & 0 & 20 & 0 & 100 \\
\hline 12.Communicative English Intermediate & 0 & 0 & 0 & 0 & 0 & 0 & 25 & 0 & 0 & 0 & 0 & 0 & 60 & 0 & 0 & 0 & 0 & 15 & 0 & 100 \\
\hline 13.Sign Language & 40 & 0 & 0 & 0 & 0 & 0 & 0 & 0 & 0 & 0 & 0 & 0 & 0 & 0 & 0 & 0 & 0 & 50 & 10 & 100 \\
\hline 14.Life \& Symbiosis & 20 & 0 & 5 & 25 & 0 & 10 & 0 & 40 & 0 & 0 & 0 & 0 & 0 & 0 & 0 & 0 & 0 & 0 & 0 & 100 \\
\hline 15.Global Environment & 90 & 0 & 0 & 0 & 0 & 0 & 0 & 0 & 0 & 0 & 0 & 0 & 0 & 0 & 0 & 0 & 10 & 0 & 0 & 100 \\
\hline 16.Mathematics & 0 & 0 & 0 & 0 & 50 & 0 & 0 & 0 & 0 & 0 & 0 & 0 & 0 & 0 & 0 & 0 & 0 & 0 & 50 & 100 \\
\hline 17.Statistics & 0 & 0 & 0 & 25 & 25 & 0 & 0 & 0 & 0 & 0 & 0 & 0 & 0 & 0 & 0 & 0 & 0 & 0 & 50 & 100 \\
\hline 18.Physics & 35 & 0 & 0 & 0 & 35 & 0 & 0 & 0 & 0 & 0 & 0 & 0 & 0 & 0 & 0 & 0 & 0 & 0 & 30 & 100 \\
\hline 19.Chemistry & 28.5 & 0 & 0 & 0 & 21 & 0 & 28.5 & 8 & 0 & 0 & 0 & 0 & 8 & 0 & 3 & 0 & 3 & 0 & 0 & 100 \\
\hline 20.Mystery of the Human Body & 30 & 0 & 0 & 10 & 0 & 0 & 20 & 0 & 0 & 10 & 10 & 0 & 10 & 0 & 0 & 0 & 0 & 10 & 0 & 100 \\
\hline 21.Life science & 40 & 0 & 0 & 0 & 20 & 15 & 0 & 0 & 0 & 0 & 0 & 0 & 20 & 0 & 0 & 0 & 5 & 0 & 0 & 100 \\
\hline 22.Safety Science & 20 & 20 & 0 & 20 & 0 & 0 & 0 & 0 & 0 & 0 & 0 & 0 & 0 & 0 & 0 & 20 & 0 & 0 & 20 & 100 \\
\hline 23.Agriculture & 20 & 25 & 0 & 0 & 0 & 5 & 10 & 17.5 & 0 & 0 & 0 & 0 & 5 & 0 & 0 & 12.5 & 5 & 0 & 0 & 100 \\
\hline 24.Introduction to Programming & 0 & 0 & 0 & 0 & 30 & 0 & 0 & 0 & 0 & 0 & 0 & 45 & 0 & 0 & 0 & 0 & 25 & 0 & 0 & 100 \\
\hline 25.Philosophy & 0 & 0 & 0 & 0 & 25 & 50 & 0 & 0 & 0 & 0 & 0 & 0 & 25 & 0 & 0 & 0 & 0 & 0 & 0 & 100 \\
\hline 26. Theory of Arts and Culture & 35 & 0 & 0 & 0 & 0 & 0 & 40 & 0 & 0 & 0 & 25 & 0 & 0 & 0 & 0 & 0 & 0 & 0 & 0 & 100 \\
\hline 27.Literature & 10 & 0 & 0 & 0 & 20 & 0 & 0 & 0 & 0 & 0 & 10 & 0 & 40 & 0 & 0 & 10 & 0 & 10 & 0 & 100 \\
\hline 28.Current Events in the World & 35 & 0 & 0 & 0 & 0 & 0 & 25 & 20 & 0 & 0 & 0 & 20 & 0 & 0 & 0 & 0 & 0 & 0 & 0 & 100 \\
\hline 29.Modern Sociology & 20 & 0 & 0 & 20 & 30 & 30 & 0 & 0 & 0 & 0 & 0 & 0 & 0 & 0 & 0 & 0 & 0 & 0 & 0 & 100 \\
\hline 30.Economics & 0 & 30 & 0 & 0 & 30 & 0 & 20 & 0 & 0 & 0 & 0 & 0 & 20 & 0 & 0 & 0 & 0 & 0 & 0 & 100 \\
\hline 31.Clinical Psychology & 0 & 0 & 24 & 0 & 0 & 24 & 0 & 0 & 0 & 0 & 0 & 0 & 24 & 0 & 0 & 0 & 0 & 24 & 4 & 100 \\
\hline 32.Human Relations Theory & 0 & 0 & 24 & 0 & 0 & 24 & 0 & 0 & 0 & 0 & 0 & 0 & 23 & 0 & 0 & 0 & 0 & 24 & 5 & 100 \\
\hline 33.Education \& Human & 60 & 0 & 0 & 0 & 0 & 0 & 0 & 0 & 0 & 0 & 0 & 0 & 20 & 0 & 0 & 0 & 0 & 20 & 0 & 100 \\
\hline 34.Collaboration with the Community I & 0 & 10 & 0 & 0 & 0 & 0 & 0 & 0 & 0 & 0 & 50 & 0 & 0 & 0 & 10 & 10 & 10 & 0 & 10 & 100 \\
\hline 35.Disaster and Community Development & 0 & 0 & 0 & 0 & 0 & 0 & 0 & 25 & 25 & 0 & 0 & 0 & 0 & 0 & 0 & 25 & 25 & 0 & 0 & 100 \\
\hline 36.Community Design & 0 & 0 & 0 & 15 & 15 & 15 & 0 & 10 & 0 & 0 & 0 & 25 & 20 & 0 & 0 & 0 & 0 & 0 & 0 & 100 \\
\hline 37.Life Design & 0 & 0 & 0 & 15 & 15 & 0 & 10 & 10 & 0 & 0 & 0 & 35 & 15 & 0 & 0 & 0 & 0 & 0 & 0 & 100 \\
\hline 38.The Constitution of Japan & 35 & 0 & 0 & 0 & 20 & 0 & 0 & 0 & 0 & 0 & 20 & 0 & 10 & 0 & 0 & 10 & 0 & 5 & 0 & 100 \\
\hline 39.Life \& Ethics & 0 & 60 & 0 & 0 & 0 & 20 & 0 & 0 & 0 & 0 & 0 & 0 & 10 & 0 & 0 & 0 & 10 & 0 & 0 & 100 \\
\hline 40.Japanese History & 20 & 0 & 20 & 0 & 20 & 15 & 0 & 0 & 0 & 0 & 0 & 0 & 25 & 0 & 0 & 0 & 0 & 0 & 0 & 100 \\
\hline
\end{tabular}

In 1991, MEXT recommended a self-review, self-evaluation system to improve the quality of higher education and research in Japan [19]. In a 2008 report by MEXT's CCE, ongoing efforts to enhance the general quality of higher education in Japan, including the use of curriculum 
maps for self-review and evaluation, were underscored [20]. Curriculum maps have thus come to play a key role in understanding and achieving learning outcomes [21]. In 1976, Walter Wager created instructional curriculum mapping (ICM) at Yamaguchi University (in Japan) as a way to visualize each item in a given curriculum [22][23][24] and improve curricula.

Curriculum maps are useful for students who need to understand the relationships among courses and lectures as they study. When teachers design or plot curriculum maps, they are required to choose $\mathrm{x}$ and $\mathrm{y}$ axes. In many cases, such plotting is discussed among faculty during faculty development activities. Recently, independently run organizations responsible for the evaluation of Japanese universities have enforced the use of curriculum mapping as a standard tool for curriculum assessment. This means that most universities have to create curriculum maps.

However, it is difficult to create a single curriculum map that includes all the curricula of a given college or university; ideally, this would also be done annually. To assist faculty and address the problems involved in the ICM process, this study proposes a novel kind of curriculum mapping procedure, which utilizes a combination of cosine similarity, multidimensional scaling (MDS), and scatter plotting [25]. We call this method dynamic curriculum mapping (DCM).

\subsection{Dynamic Curriculum Mapping}

DCM is a virtual method that differs from usual manual curriculum mapping methods. Since DCM is created based on the distribution of words in syllabi, and some syllabi that are similar might use different technical or keywords, DCM will also produce results that are different from those of manual curriculum mapping. To address this problem, we employ the 19 competencies, rather than the distribution of words in syllabi, to visualize curricula. In Japan, Kuwada et al. developed curriculum mapping using Microsoft Excel [26]. And usually curriculum mapping was constricted by teachers. In Yamagata University, curriculum mapping is performed using a curriculum numbering map [27]. However, the curriculum mapping here is not interactive. Therefore, we believe that, apart from our system, no interactive curriculum mapping systems have been developed.

\subsection{Preparing to Analyze the Data}

As a part of current university reform efforts, our team prepared 40 syllabi for common liberal and general education courses; our university began offering these common liberal and general education courses in 2017. We designed the syllabi of these courses to have two noteworthy features. The first is that the course syllabi show relationships between the courses and the 19 Tokiwa competencies, in order to help students easily understand the aims of the courses.

This feature is in addition to the content and plan of the courses, which teachers have always included in syllabi. The addition of the competencies to the syllabi enables students and teachers to have a common understanding of the goals of the course.

The second feature that the team added to liberal and general education course syllabi was the rubric based on the 19 Tokiwa competencies. Students are thus able to evaluate the competencies 
that they should achieve in the course in the context of all the possible competencies. The rubric revealing relationships between all the courses and competencies is displayed in Table 2 .

\section{Methods}

Cosine similarity can be used to measure similarities and detect differences between vectors. The cosine similarity of vectors $\vec{a}$ and $\vec{b}$ is defined as:

$$
\cos (\vec{a}, \vec{b}):=\frac{\vec{a} \cdot \vec{b}}{|\vec{a}||\vec{b}|}=\frac{\sum_{i=1}^{|V|} a_{i} b_{i}}{\sqrt{\sum_{i=1}^{|V|} a_{i}^{2}} \cdot \sqrt{\sum_{i=1}^{|V|} b_{i}^{2}}}
$$

In this paper, a vector is a syllabus or a course's pattern of 19 competencies. Thus, herein, cosine similarity measures the similarity between two syllabi or courses (Table 2) and a course can be regarded as a vector with 19 dimensions; we can therefore calculate total cosine similarity between two courses. The maximum value of cosine similarity is 1 and the minimum is -1 .

When two syllabi or competencies are the same, their cosine similarity is 1 . The number of possible relationships between two courses is ${ }_{40} \mathrm{C}_{2}=780$. We therefore obtain cosine similarity metrics in 780 dimensions, meaning that for visualization purposes, we also needed to reduce the dimensionality of this analysis method.

Methods of reducing dimensions can generally be classified into two types: linear and nonlinear. Linear methods involve methods such as Random Projection [28], PCA [29], Linear Discriminant Analysis [30], and MDS [31]. Nonlinear methods include Isomap [32], Locally Linear Embedding [33], Modified Locally Linear Embedding (MLLE) [34], Hessian Eigenmapping [35], local tangent space alignment [36], and t-distributed stochastic neighbor embedding (t-SNE) [37]. In this study, we opted for the MDS method to visualize the cosine similarity matrix, because it is perhaps the easiest to understand.

The conventional way of visualizing a cosine similarity matrix is to map it onto distance space, thereby reducing this high dimensionality to low dimensionality (two dimensions). Unfortunately, the cosine similarity of the two vectors in the vector space is unlikely to involve distance axioms in a general mathematical sense (e.g., based on non-negativity, non-degradability, symmetry, triangular inequality), because cosine similarity can be negative. When any $x, y, z$ belonging to the set $\mathrm{X}$ satisfy these four arbitrary guidelines against two real variable functions $d: \mathrm{X} \times \mathrm{X} \rightarrow \mathbf{R}$, defined on the set $\mathrm{X}, d$ represents their distance, and $(\mathrm{X}, d)$ represents their distance space in a general mathematical sense.

(1) non-negativity:

$$
\begin{aligned}
& d(x, y) \geq 0 \\
& x=y \Rightarrow d(\mathrm{x}, \mathrm{y})=0 \\
& d(x, y)=d(y, x), \\
& d(x, y)+\mathrm{d}(y, z) \geq d(x, z)
\end{aligned}
$$$$
\text { (2) non-degradability: }
$$$$
\text { (3) symmetry: }
$$$$
\text { (4) triangular inequality: }
$$ 
Therefore, when using the visualization method described above, for practical purposes, it is necessary to subtract from 1 . This way, non-negativity can be guaranteed and mapped onto the distance space. After this mapping, the maximum value of cosine similarity becomes 2 and the minimum value becomes 0 . This mapping also satisfies the principles of non-degradability, symmetry, and triangular inequality.

When trying to visualize the $(x, y)$ components obtained by dimensional reduction, a scatter plot may be of use; however, it may be difficult to understand the meaning of the $\mathrm{x}$ and $\mathrm{y}$ axes. For simplicity, in this study, the $\mathrm{x}$-axis and the $\mathrm{y}$-axis are images corresponding to the first axis and the second axis of the principal component analysis. That is, the $\mathrm{x}$ and $\mathrm{y}$ axes are derived by calculations that mathematically reduce dimensions.

To calculate the cosine similarity of syllabi, we prepared a vector space in which each vector represented the syllabus of a course offered by Kobe Tokiwa University in 2017. Each syllabus is freely available on the institution's official homepage [18]. We prepared each syllabus in portable document format (PDF), and then converted these files to plain text using an open-source UNIX command-line tool called pdftotext, which encodes the text using UTF-8 [38]. We then

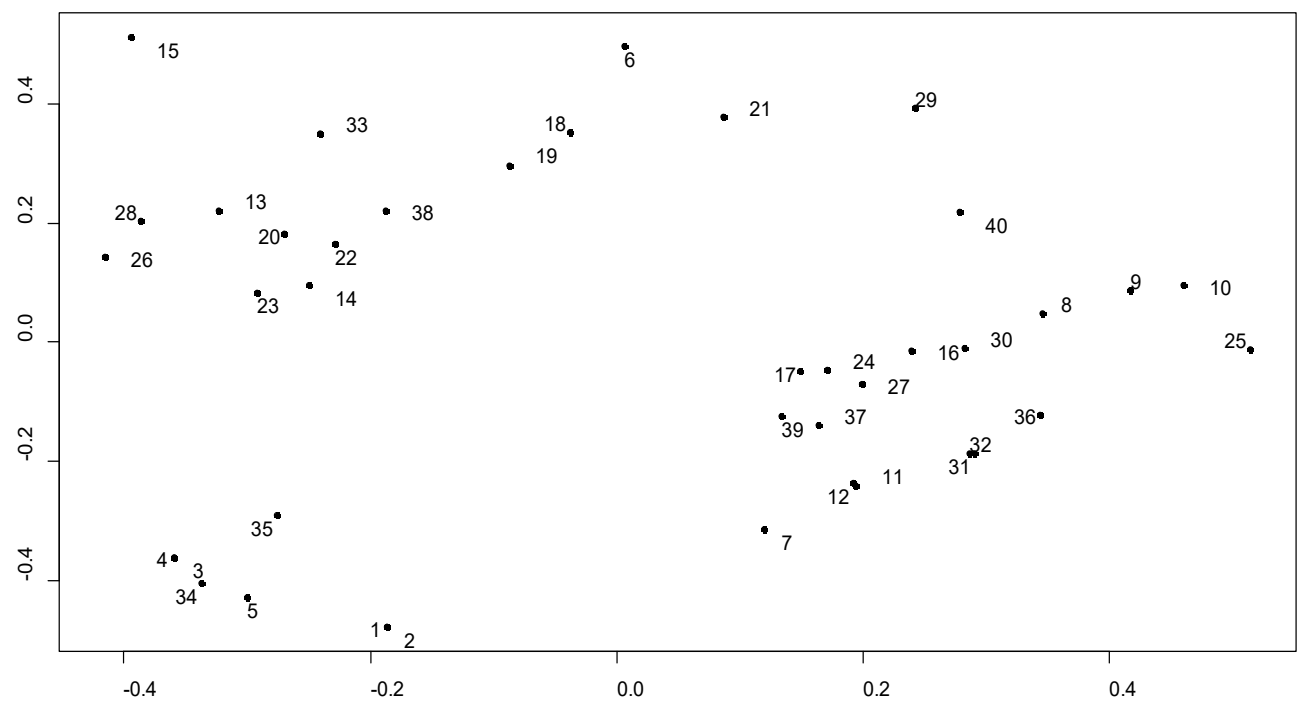

Figure 1: Visualizing curricula using syllabi: using 19 competencies for 40 courses, we visualized MDS via scatter plotting.

performed a morphological analysis of the Japanese language in each file using $\mathrm{MeCab}$ [39]. Finally, we calculated cosine similarity using files produced with MeCab.

We visualized the resulting cosine similarity matrix with MDS, using the R package "lsa" (latent semantic analysis) [40], as well as by using scatter plotting with R's "maptools" package [41][42]. We also used Cytoscape [43], a network visualization tool developed for the analysis 
of protein-protein interactions (PPI), to visualize the interrelationships between courses and compe-tencies (Figure 1). Network visualization is underpinned by graph theory.

\section{Results}

To visualize curricula using competencies, we calculate cosine similarity, MDS, and scatter plotting (Figure 1). There are three groups in Figure 1. The first group took Pleasant \& Deep Learning I, Pleasant \& Deep Learning II, Freshman Seminar I, Freshman Seminar II, Leadership $\&$ Facilitation, Collaboration with the Community I, and Disaster and Community Development. The second group took Sign Language, Life \& Symbiosis, Global Environment, Mystery of the Human Body, Safety Science, Agriculture, Theory of Arts and Culture, Current Events in the World, Education \& Human, and The Constitution of Japan. The third group took Health \& Sports Science II, Academic writing, English Communication I, English Communication II,

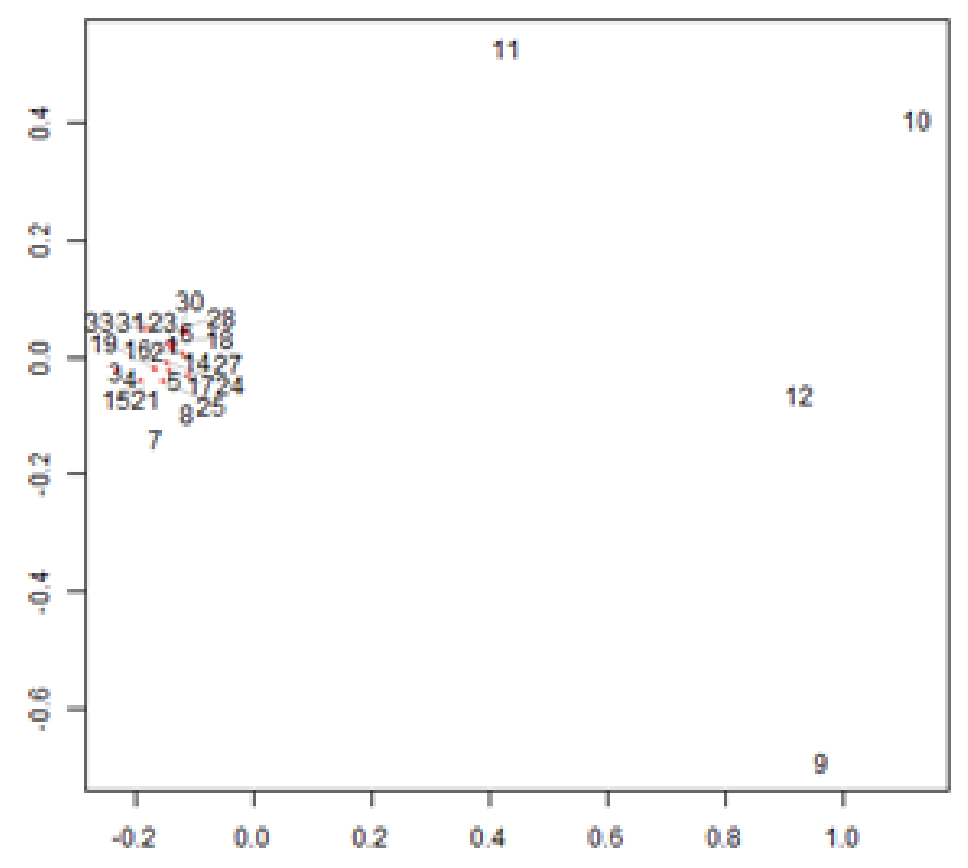

Figure 2: Curricula, visualized by employing syllabi; using syllabi from 39 courses, we visualized MDS via a scatter plotting (cited from [39]).

Communicative English Basic, Communicative English Intermediate, Mathematics, Statistics, Introduction to Programming, Philosophy, Literature, Economics, Community Design, Life Design, and Life \& Ethics.

These different groups' different courses do not superficially appear to be related, but the visualized curricula in fact show some overlap in the competencies that they cover. This finding is very important, as it may provide students with more helpful guidance in selecting their courses. For example, if students want to obtain a wide range of competencies, they will see that they have to choose courses from different groups. Note that scatter plotting of MDS is relative, so it will 


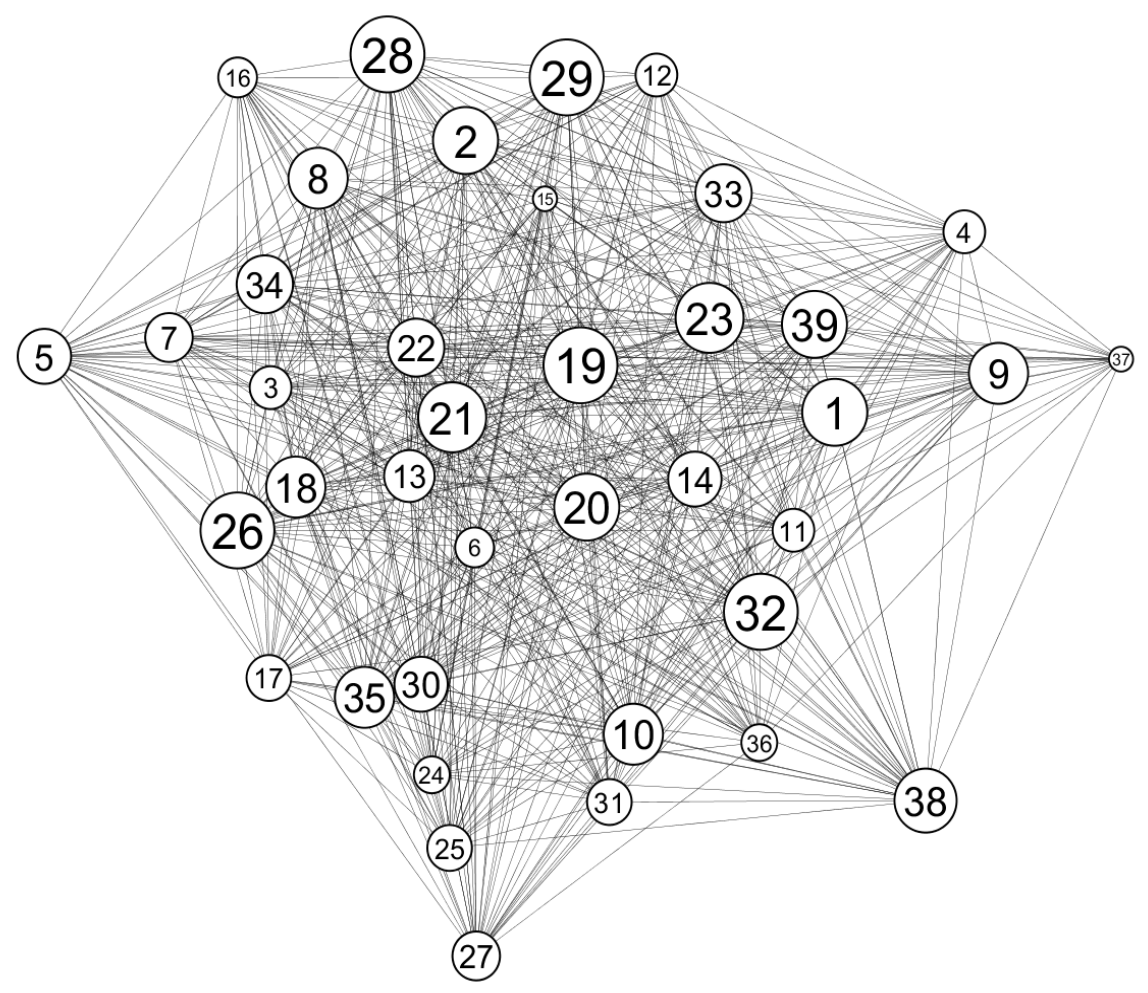

Figure 3: A network, visualized; using 19 competencies from 39 courses, we visualized this network with Cytoscape (cited from [39]).

change if courses are added or deleted. However, scatter plots of MDS may be useful for advising students, regardless of whether these plots change or not.

We visualized curricula by employing syllabi from 39 courses, instead of competencies (Figure 2, cited from [44]). As there is only one big group, it is possible to understand that this map is not useful in comparison with both curriculum maps, which were developed by humans; it is also possible to visualize curricula using competencies.

For visualizing curricula using network analysis, we obtained the symmetric matrix of cosine similarity. This matrix-vector is known as an adjacency matrix in network analysis. Next, we transformed the adjacency matrix into an adjacency list using the igraph library [45]. We visualized these data using the open-source software Cytoscape [43] (Figure 3, cited from [44]). Since this figure shows too many connections, it is difficult to clearly understand the relationships among courses. 


\section{Discussion and Implications}

We believe that using MDS to visualize curricula is the best way for students to understand course competencies and select their courses. These methods work better using syllabi or network visualization.

Global competency here refers to the knowledge and skills that people need to understand today's "flat world" and to integrate across disciplines, so that they can comprehend global events and create possibilities to address them. Global competencies also include the attitudinal and ethical dispositions that make it possible to interact peacefully, respectfully, and productively with fellow human beings from diverse geographies [46].

Thus, competency-based education, which is an approach to teaching and learning more often used in learning concrete skills than in abstract learning, has become a hot topic in higher education circles. However, the competency-based education approach has just been initiated in Japan. The Organization for Economic Co-operation and Development (OECD) has defined core competencies [47]. The Programme for International Student Assessment (PISA), which is conducted by OECD, was developed based on these core competencies.

At present, Kobe Tokiwa University is undergoing reforms, one of which is a move to competency-based education. As discussed above, our university developed a common evaluation indicator called "Tokiwa competencies," which students should acquire through regular, quasi-regular (or remedial), and extracurricular (or club) activities. We believe 19 Tokiwa competencies is too many in number. Therefore, we aim to re-define Tokiwa competencies and reduce the number of competencies.

While most students previously selected their courses based solely on content, these competencies will provide students with an expanded perspective to assist them in course selection. We developed an Information and Communication Technology-based support system to help students select university-level courses. Since 2017, the syllabi of Kobe Tokiwa University display the relationships between courses and the Tokiwa competencies (Table 2).

As such, students can now calculate the theoretical competencies when selecting their courses. We developed a web-based system to facilitate the calculation of competencies. Students first select their preferred courses and enter them on the webpage; the competencies are then illustrated as a radar chart reflecting the 19 categories. While this radar chart is theoretical and represents ideal competency values, it is useful for understanding the types of competencies that may be obtained from the courses (Figure 4). 


\section{(- $\Rightarrow$ http://icepl2017demo.tekij... O-c \& icepl2017demo.tekijuku.net $x$}

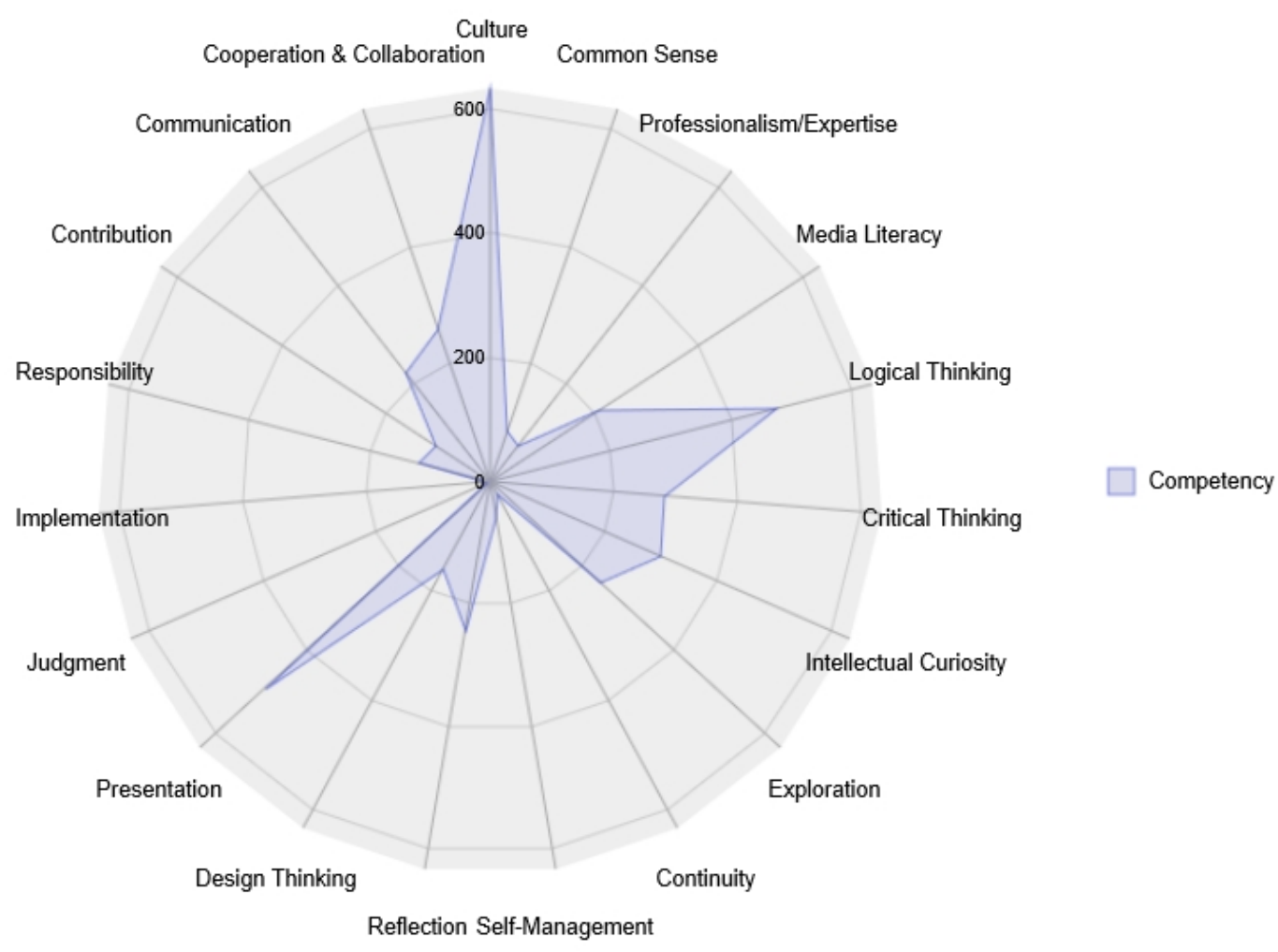

Figure 4. Rader Chart of Competencies Corresponding to Academic Skills and Deep Learning I, Academic Skills and Deep Learning II, Information Technology Basics, Academic Writing, English Communication I, English Communication II, and Life and Ethics. Source: Takamatsu et al. [48]. Web-based Support System for Students to Select Courses using Tokiwa Competencies. International Conference on Education, Psychology, and Learning (ICEPL 2017).

We further developed a web-based radar chart system of Tokiwa competencies to help students understand their competency level by themselves. Students first select their current competency level on the webpage; the competencies are then illustrated as a radar chart showing the 19 categories (Figure 5). This system is compatible with both computers and smartphones, which is necessary given that most students use a smartphone instead of a computer. This feature has been created with the hope that students understand each competency easily, and that this would reflect in their behavior in regular and quasi-regular curricula, as well as extracurricular activities in university. 


\begin{tabular}{|c|c|c|c|c|c|c|}
\hline$\square$ icepl2018demo.tekijuk & $\times+$ & & & - & $\square$ & $\times$ \\
\hline$\langle\quad\rangle$ & icepl2018demo.tekijuku.net/test01.cgi & [1]) & $\equiv$ & 0 & 8) & $\cdots$ \\
\hline
\end{tabular}

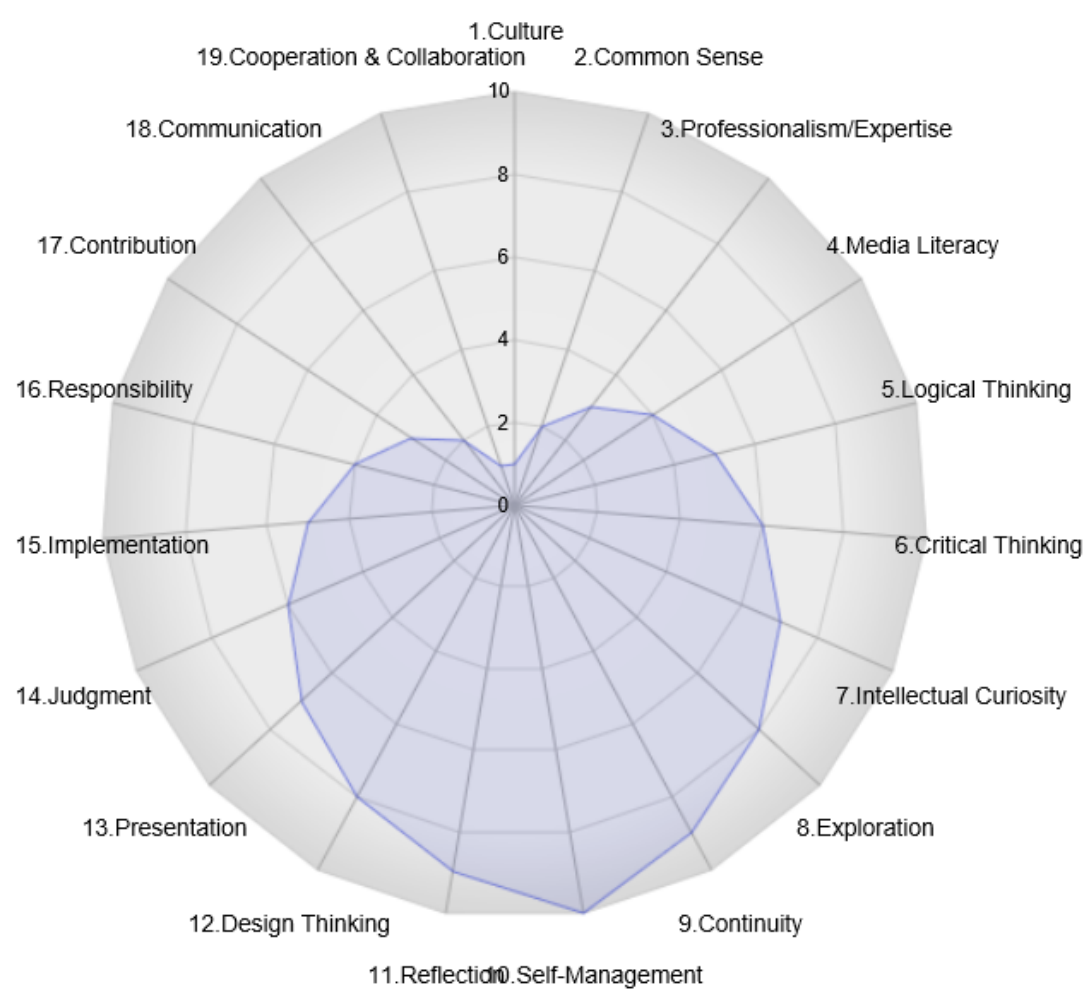

Competency

Figure 5. Example of a radar chart. Source: Takamatsu et al. [7]. Web-based Radar Chart System of Tokiwa Competencies, International Conference on Education, Psychology, and Learning (ICEPL 2018).

In this study, we visualized curricula using competencies via a combination of cosine similarity, MDS, and scatter plotting. Using this study, we have already initiated the attempt to advise students based on their desired competencies. A detailed analysis of the results and impact will be reported in another article.

\section{References}

[1] K. Takamatsu, T. Kirimura, K. Bannaka, I. Noda, M. Omori, R. Adachi, K. Mitsunari, T. Nakamura, and Y. Nakata, "SWOT analysis and complex network analysis to enhance governance in universities by collaboration between faculty and staff," $A d v$. Appl. Informatics (IIAI-AAI), 2016 5th IIAI Int. Congr. on. IEEE, pp. 1188-1189, 2016.

[2] T. Krimura, K. Takamatsu, K. Bannaka, I. Noda, K. Mitsunari, and Y. Nakata, "Innovate the management of teaching and learning at our own university through 
collaboration between academic faculty and administrative staff," Bull. Kobe Tokiwa Univ., vol. 10, pp. 23-32, 2017.

[3] M. Shinoda, "Necessity of staff to constract and promote teaching management cycle," Between, vol. Apr-May, pp. 23-32, 2013.

[4] MEXT, "Toward the construction of undergraduate education," Central Council for Education, 2008. [Online]. Available:

http://www.mext.go.jp/b_menu/shingi/chukyo/chukyo4/houkoku/080410.htm. [Accessed: 28-Jun-2018].

[5] Between Editorial Department, "Connection between three policies," Between, vol. Spring, p. 1, 2008.

[6] MEXT, "Connection reform of high school and university," Ministry of Education, Culture, Sports, Science, and Technology, 2014. [Online]. Available: http://www.mext.go.jp/b_menu/shingi/chukyo/chukyo0/toushin/1354191.htm. [Accessed: 28-Jun-2018].

[7] K. Takamatsu, Y. Kozaki, K. Murakami, E. Matsumoto, M. Bohgaki, M. Seki, A. Imanishi, K. Bannaka, I. Noda, K. Mitsunari, and Y. Nakata, "Web-based Radar Chart System of Tokiwa Competencies in Eduinformatics," Int. Conf. Educ. Psychol. Learn., pp. 30-37, 2018.

[8] W. G. Spady, Outcome-based education: Critical Issues and Answers. 1994.

[9] "Ehime University Competencies Standards for Students: EUCS-S," Ehime University, 2012. [Online]. Available: https://www.ehime-u.ac.jp/overview/competency/.

[Accessed: 15-Sep-2018].

[10] "Educating employment skills based on eight competencies," Kansai Gaidai University, 2010. [Online]. Available: https://www.kansaigaidai.ac.jp/special/gp/gp2010_univ/univ01.html.

[11] “Competency development program," Kanto Gakuen University. [Online]. Available: http://www.kanto-gakuen.ac.jp/univer/academics/competency.htm. [Accessed: 15-Sep-2018].

[12] J. Oba, "Curriculum management practices from the perspective of studies of university staff and academic-administrative collaboration," J. Jpn Assoc Coll Univ. Educ, vol. 36, no. 1, pp. 53-58, 2014.

[13] MEXT, "Means to be staff in university," Ministry of Education, Culture, Sports, Science, and Technology, 2017. [Online]. Available: 
http://www.mext.go.jp/b_menu/shingi/chukyo/chukyo4/015/attach/1380986.htm.

[14] T. Krimura, K. Takamatsu, K. Bannaka, I. Noda, and Y. Nakata, "Knowledge creation through collaboration between academic and administrative faculty: Strategies of raise chance of the serendipity," Bull. Kobe Tokiwa Univ., vol. 9, pp. 71-78, 2016.

[15] T. Kirimura, K. Takamatsu, K. Bannaka, I. Noda, M. Omori, R. Adachi, K. Mitsunari, and Y. Nakata, "Three-step knowledge network model," Bull. Kobe Tokiwa Univ., vol. 9, pp. 79-86, 2016.

[16] K. Takamatsu, K. Bannaka, T. Kirimura, I. Noda, K. Murakami, K. Mitsunari, and Y. Nakata, "Tag-based knowledge network models," Bull. Kobe Tokiwa Univ., vol. 10, pp. 51-60, 2017.

[17] K. Tamiya, "The significance, introduction, and how to use of the rubric," Forum Cent. Teach. Learn. Teikyo Univ, vol. 1, pp. 125-135, 2014.

[18] "Syllabus of Kobe Tokiwa University," Kobe Tokiwa University, 2017. [Online]. Available: available: http://www.kobe-tokiwa.ac.jp/univ/. [Accessed: 28-Jun-2018].

[19] MEXT, "Policy of education in Japan," Ministry of Education, Culture, Sports, Science, and Technology, 1991. [Online]. Available:

http://www.mext.go.jp/b_menu/hakusho/html/hpad199101/. [Accessed: 28-Jun-2018].

[20] MEXT, "Construction of education for university," Ministry of Education, Culture, Sports, Science, and Technology, 2008. [Online]. Available: http://www.mext.go.jp/b_menu/shingi/chukyo/chukyo4/houkoku/080410.htm.

[Accessed: 28-Jun-2018].

[21] MEXT, “Glossary,” Ministry of Education, Culture, Sports, Science, and Technology, 2014. [Online]. Available:

http://www.mext.go.jp/component/b_menu/shingi/toushin/_icsFiles/afieldfile/2013/0 5/13/1212958_002.pdf. [Accessed: 28-Jun-2018].

[22] W. Wager, "Instructional Curriculum Mapping," ERIC, 1976. [Online]. Available: http://eric.ed.gov/?id=ED141264. [Accessed: 28-Jun-2018].

[23] D. Kazui, S. Maeda, and Y. Shirakawa, "Theory and Practice of curriculum mapping," Lib. Gen. Educ. Soc. Japan, pp. 116-117, 2010.

[24] T. Ogawa, "A study of systematic curriculum improvement towards guaranteeing the quality of undergraduate education: a curriculum improvement trial based on faculty develop-ment for improvement of undergraduate education," Bull. Kyoto Univ. Res. 
High. Educ., vol. 16, pp. 13-24, 2010.

[25] K. Takamatsu, K. Murakami, R.-J. W. Lim, and Y. Nakata, "Novel visualization for curriculum in silico using syllabus by a combination of cosine similarity, multidimensional scaling methods, and scatter plot: Dynamic curriculum mapping (MCD) for syllabus," Bull. Kobe Tokiwa Univ., vol. 10, pp. 99-106, 2017.

[26] M. Kuwada, Y. Ando, K. Nishi, J. Nakamura, and K. Tanaka, “The Curriculum Map as an Assessment Tool for Quality Assuranace of Education," Bull. Univ. ElectroCommunications, vol. 25, no. 1, pp. 41-50, 2013.

[27] M. Yoshida, "A Proposal of Curriculum Improvement System using a Curriculum Numbering Map and Persona Marketing," Bull. Teach. Train. Res. Cent. Attach. to Facully Educ. Art Sci. Yamagata Univ., vol. 10, pp. 9-17, 2015.

[28] E. Bingham, E. Bingham, H. Mannila, and H. Mannila, "Random projection in dimensionality reduction: applications to image and text data," Int. Conf. Knowl. Discov. Data Min., 2001.

[29] K. Pearson, "LIII. On lines and planes of closest fit to systems of points in space," Philos. Mag. Ser. 6, 1901.

[30] R. A. Fisher, "The use of multiple measures in taxonomic problems," Ann. Eugen., 1936.

[31] J. B. Kruskal, "Multidimensional scaling by optimizing goodness of fit to a nonmetric hypothesis," Psychometrika, vol. 29, no. 1, pp. 1-27, 1964.

[32] J. B. Tenenbaum, V. De Silva, and J. C. Langford, "A global geometric framework for nonlinear dimensionality reduction," Science (80-. )., vol. 290, no. 5500, pp. 2319$2323,2000$.

[33] S. T. Roweis and L. K. Saul, "Nonlinear dimensionality reduction by locally linear embedding.," Science, vol. 290, no. 5500, pp. 2323-2326, 2000.

[34] Z. Zhang and J. Wang, "MLLE: Modified Locally Linear Embedding Using Multiple Weights," Adv. Neural Inf. Process. Syst., pp. 1593-1600, 2006.

[35] D. L. Donoho and C. Grimes, "Hessian eigenmaps: Locally linear embedding techniques for high-dimensional data," Proc. Natl. Acad. Sci., vol. 100, no. 10, pp. 5591-5596, 2003.

[36] Z. Y. Zhang and H. Y. Zha, "Principal manifolds and nonlinear dimensionality reduction via tangent space alignment," J. Shanghai Univ., vol. 8, no. 4, pp. 406-424, 2004. 
[37] L. J. P. Van Der Maaten and G. E. Hinton, "Visualizing high-dimensional data using t-sne," J. Mach. Learn. Res., vol. 9, pp. 2579-2605, 2008.

[38] "pdftotext." [Online]. Available: http://www.foolabs.com/xpdf/download.html. [Accessed: 28-Jun-2018].

[39] T. Kudo, "MeCab: Yet Another Part-of-Speech and Morphological Analyzer," 2005. [Online]. Available: http://mecab.googlecode.com/svn/trunk/mecab/doc/index.html. [Accessed: 28-Jun-2018].

[40] F. Wild, "lsa: Latent semantic analysis," $R$ package version 0.73.1, 2015. [Online]. Available: ttps://cran.r-project.org/package=1sa. [Accessed: 28-Jun-2018].

[41] N. Lewin-Koh and R. Bivand, "maptools: Tools for reading and handling spatial objects," $R$ package version .... 2011.

[42] R core team, "R: A language and environment for statistical computing.," $R$ Found. Stat. Comput. Vienna, Austria., 2017.

[43] P. Shannon, A. Markiel, O. Ozier, N. S. Baliga, J. T. Wang, D. Ramage, N. Amin, B. Schwikowski, and T. Ideker, "Cytoscape: A software Environment for integrated models of biomolecular interaction networks," Genome Res., vol. 13, no. 11, pp. 2498-2504, 2003.

[44] K. Takamatsu, K. Murakami, T. Kirimura, K. Bannaka, I. Noda, M. Yamasaki, L. Rahpael-Joe, 1 Wei, K. Mitsunari, T. Nakamura, and Y. Nakata, "A new way of visualizing curricula using competencies: Cosine similarity, multidimensional scaling methods, and scatter plotting," Adv. Appl. Informatics (IIAI-AAI), 2017 6th IIAI Int. Congr. on. IEEE, pp. 192-197, 2017.

[45] G. Csárdi and T. Nepusz, "The igraph software package for complex network research,” 2006. [Online]. Available: http://igraph.org. [Accessed: 28-Jun-2018].

[46] J. E. Cohen and M. B. Malin, International perspectives on the goals of universal basic and secondary education. 2012.

[47] "competency framework," OECD. [Online]. Available: http://www.oecd.org/careers/competency_framework_en.pdf. [Accessed: 15Sep-2018].

[48] T. Kunihiko, M. Katsuniko, K. Takafumi, B. Kenya, N. Ikuhiro, M. Kenichiro, and N. Yasuo, "Web-based Support System for Students to Select Courses using Tokiwa Competencies," Int. Conf. Educ. Psychol. Learn., pp. 74-80, 2017. 